Contact: mstukel@fsu.edu

\title{
Predicting primary production in the southern California Current Ecosystem from chlorophyll, nutrient concentrations, and irradiance
}

\author{
Michael R. Stukel, Ralf Goericke, Michael R. Landry
}

\begin{abstract}
We investigated the processes driving variability in primary productivity in the California Current Ecosystem (CCE) in order to develop an algorithm for predicting primary productivity from in situ irradiance, nutrient, and chlorophyll (chl) measurements. Primary productivity data from seven process cruises of the CCE Long-Term Ecological Research (CCE LTER) program were used to parameterize the algorithm. An initial algorithm was developed using only irradiance to predict chl-specific productivity was found to have model-data misfit that was correlated with $\mathrm{NH}_{4}{ }^{+}$concentrations. We thus found that the best estimates of primary productivity were obtained using an equation including $\mathrm{NH}_{4}{ }^{+}$and irradiance: $\mathrm{PP} / \mathrm{Chl}=\mathrm{V}_{0 \mathrm{~m}} \times\left(1-\exp \left(-\alpha \times \mathrm{PAR} / \mathrm{V}_{0 \mathrm{~m}}\right) \times \mathrm{NH}_{4} /\left(\mathrm{NH}_{4}+\mathrm{K}_{\mathrm{S}}\right)\right.$, where $\mathrm{PP} / \mathrm{Chl}$ is chlorophyll-specific primary production in units of $\mathrm{mg} \mathrm{C} \mathrm{d}^{-1} / \mathrm{mg}$ Chl, PAR is photosynthetically active radiation (units of $\mu \mathrm{Ei} \mathrm{m}^{-2} \mathrm{~s}^{-1}$ ),

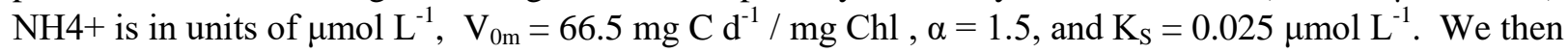
used this algorithm to compute primary productivity rates for the CCE-P1706 cruise on which in situ primary productivity samples were not available. We compared these estimates to independent productivity estimates derived from protistan grazing dilution experiments and found excellent agreement.
\end{abstract}

\section{I - Algorithm Development}

Morrow et al. (2018) tested the light dependency of phytoplankton specific growth rates by using ${ }^{14} \mathrm{C}$-PP divided by $\mathrm{Chl}$ as a proxy for phytoplankton specific growth rates. They used an equation of the form:

$P P / C h l=V_{0 m} \times\left(1-\exp \left(-\alpha \times P A R / V_{0 m}\right)\right) \times \exp \left(-\beta \times P A R / V_{0 m}\right)$

Because they were specifically focused on the ecosystem responses to interannual variability (especially El Niño), they restricted their study to measurements from the P0605, P0704, P0810, P1408, and P1604 cruises and found best fit parameters of: $\mathrm{V}_{0 \mathrm{~m}}=64 \mathrm{mg} \mathrm{C} \mathrm{d} \mathrm{m}^{-1} /$ $\operatorname{mg} \mathrm{Chl}, \alpha=1.0$, and $\beta=0.049$, when light was given as daily average PAR values in units of $\mu \mathrm{Ei}$ $\mathrm{m}^{-2} \mathrm{~s}^{-1}$. We updated these analyses by including additional data from the P1106 and P1208 "front" cruises (Krause et al. 2015; Stukel et al. 2017). With this additional data, the best fit parameter values

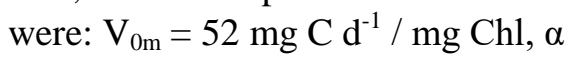

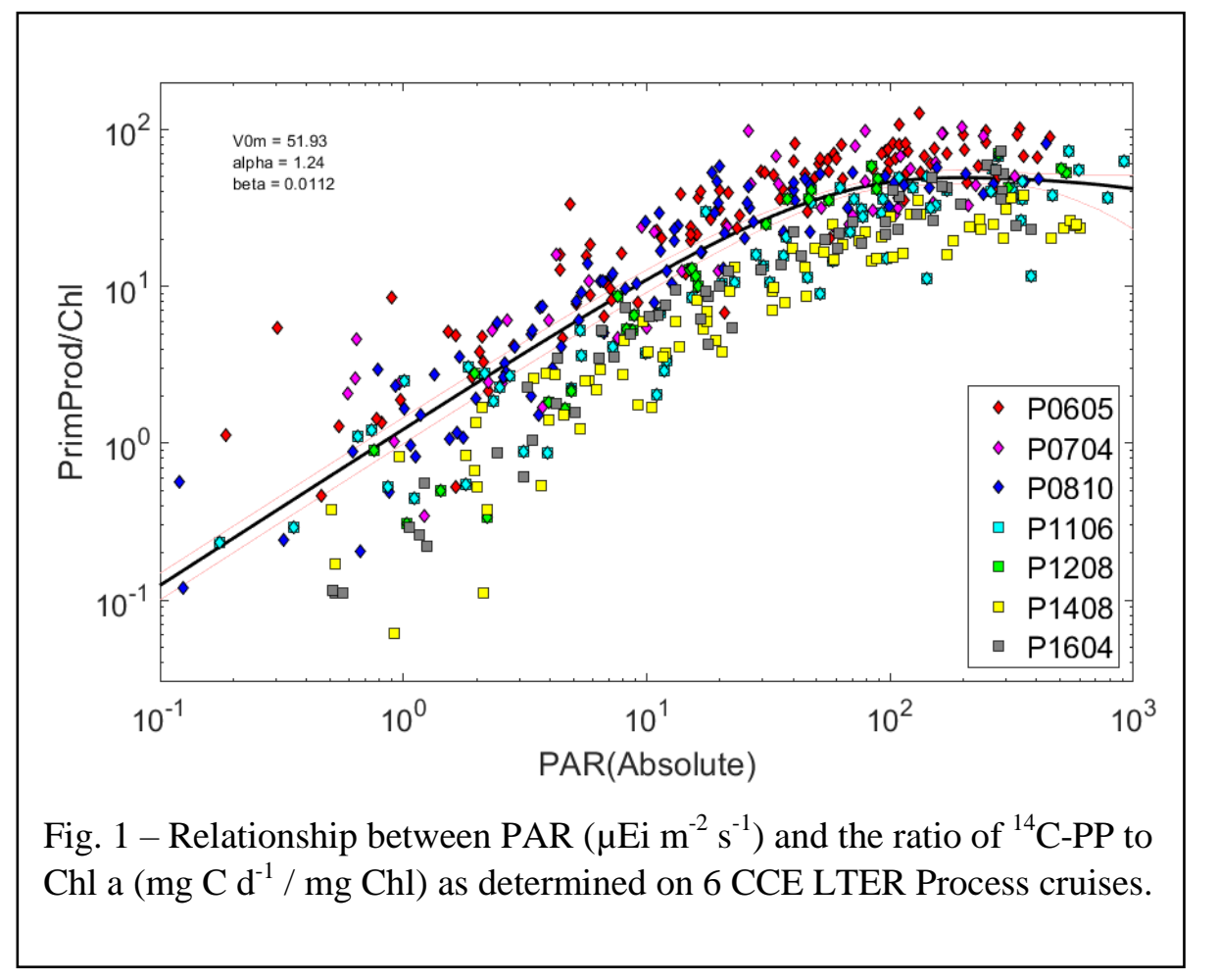


Contact: mstukel@fsu.edu

$=1.2$, and $\beta=0.011$. We then investigated the relationship between model-data misfit and nutrient concentrations to investigate whether or not nutrient limitation played an additional role in determining phytoplankton specific growth rates (Fig. 2). Although no statistically significant relationship was found between percent error and either nitrate concentration or total dissolved inorganic nitrogen $\left(\mathrm{NO}_{3}+\mathrm{NO}_{2}+\right.$ $\mathrm{NH}_{4}$ ), a relationship was found between percent error and ammonium concentration (non-parametric Spearman's $\rho=0.31, p=1.3 \times 10^{12}$ ). This suggests that Eq. 1 overestimates primary productivity when ammonium concentrations are low and underestimates it when ammonium concentrations are high.
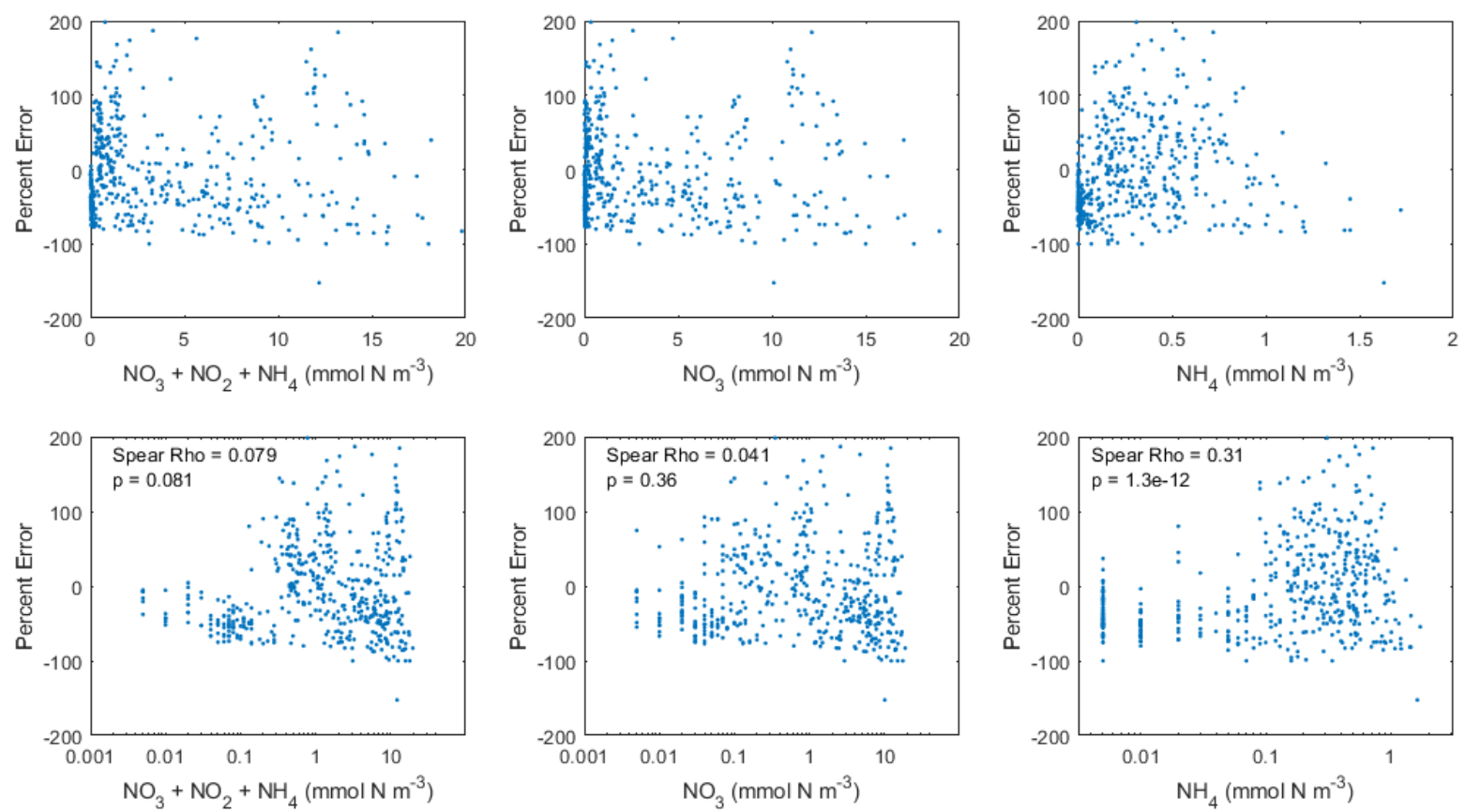

Fig. 2 - Model data misfits plotted against nutrient concentration. Bottom plots are logarithmic scaling of nutrients.

We chose to incorporate ammonium limitation of primary productivity by modeling it as a Monod function of the form: $\mathrm{LIM}_{\mathrm{NH} 4}=\mathrm{NH}_{4} /\left(\mathrm{NH}_{4}+\mathrm{K}_{\mathrm{S}}\right)$. Because this function will, by definition, set primary productivity equal to zero when $\mathrm{NH}_{4}{ }^{+}$values are reported as $0 \mu \mathrm{mol} \mathrm{L}{ }^{-1}$ (i.e., below the detection limit), we assumed that when $\mathrm{NH}_{4}^{+}$was reported as $0 \mu \mathrm{mol} \mathrm{L}{ }^{-1}$, its actual in situ value was equal to one half of the detection limit (in other words, we replaced all 0 values as $5 \mathrm{nmol} \mathrm{L}^{-1}$ ). When all of the data from P0605, P0704, P0810, P1106, P1208, P1408, and P1604 was fit to a model of the form:

$P P / C h l=V_{0 m} \times\left(1-\exp \left(-\alpha \times P A R / V_{0 m}\right)\right) \times \exp \left(-\beta \times P A R / V_{0 m}\right) \times \frac{N H_{4}}{N H_{4}+K_{S}}$

(with the constraints that $\mathrm{K}_{\mathrm{S}}, \mathrm{V}_{0 \mathrm{~m}}, \alpha$, and $\beta$ were all $\geq 0$ ) we obtained values of $\mathrm{V}_{0 \mathrm{~m}}=66.5 \mathrm{mg} \mathrm{C} \mathrm{d} / \mathrm{mg}$ Chl , $\alpha=1.5, \beta=0.0$, and $\mathrm{K}_{\mathrm{S}}=0.025$. We thus concluded that the photoinhibition term did not need to be included if $\mathrm{NH}_{4}^{+}$was used as a predictor variable and further tested the equation: 
Contact: mstukel@fsu.edu

$P P / C h l=V_{0 m} \times\left(1-\exp \left(-\alpha \times P A R / V_{0 m}\right)\right) \times$

$\frac{\mathrm{NH}_{4}}{\mathrm{NH}_{4}+\mathrm{K}_{\mathrm{S}}}$

To determine whether or not the inclusion of $\mathrm{NH}_{4}^{+}$ as a predictor variable actually increased the predictive ability of the model, we conducted a Monte Carlo analysis in which $50 \%$ of the data points were selected at random (a training data set) and used to parameterize both Eq. 1 and Eq. 3.

Model data misfits were then computed with respect to how well each algorithm predicted the half of the data points that had been withheld from the training dataset. This process was repeated 1000 times and showed that the inclusion of $\mathrm{NH}_{4}{ }^{+}$as a predictor variable typically reduced the sum of squared misfits by $\sim 25 \%$. The model with $\mathrm{NH}_{4}{ }^{+}$was a better predictor with all of the training sets.

We then quantified the uncertainty in primary productivity predicted by the algorithm by computing model-data misfits for all data points. We found (unsurprisingly) that absolute misfit was strongly correlated with both the predicted and measured value of primary productivity. However, the relative misfit $($ PercentError $=($ measurement estimate)/estimate $\times 100 \%$ ) was not correlated with measured primary productivity. Hence, we can use a constant PercentError value to determine uncertainty limits on our estimates. PercentError was not symmetric with respect to upper and lower limits. Rather, we found that $95 \%$ of measured values fell between $14 \%$ and $262 \%$ of the predicted value (Fig. 4). Similarly, $68 \%$ of measured values (i.e., one standard deviation) fell between $44 \%$ and $161 \%$ of the predicted value). We also computed the correlation between PercentError values for primary productivity measurements made at multiple depths on the same CTD casts. The median correlation across all casts was 0.18 . For measurements made at the same depths on different casts within the same cycle, the correlation in PercentError was 0.15 . These correlation values were included in error propagation when determining vertically-integrated primary productivity or cycle average productivity at specific depths.
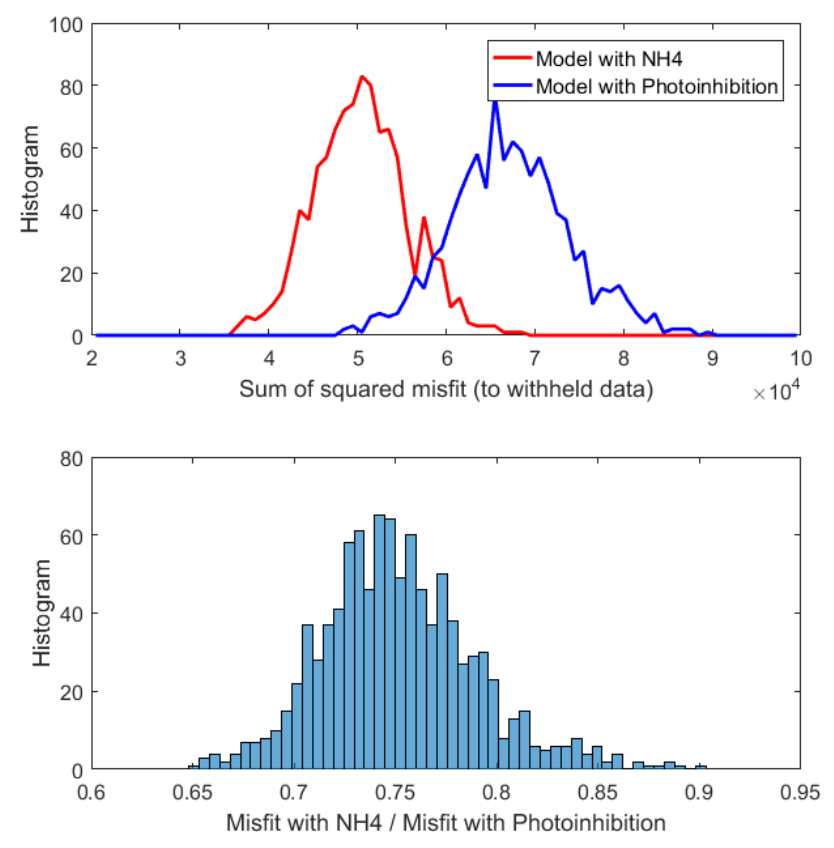

Fig. 3 - Model data misfit for Monte Carlo simulations using $50 \%$ of data as a training set and testing against the withheld data points. Model with $\mathrm{NH}_{4}$ uses Eq. 3. Model with Photoinhibition uses Eq. 1.

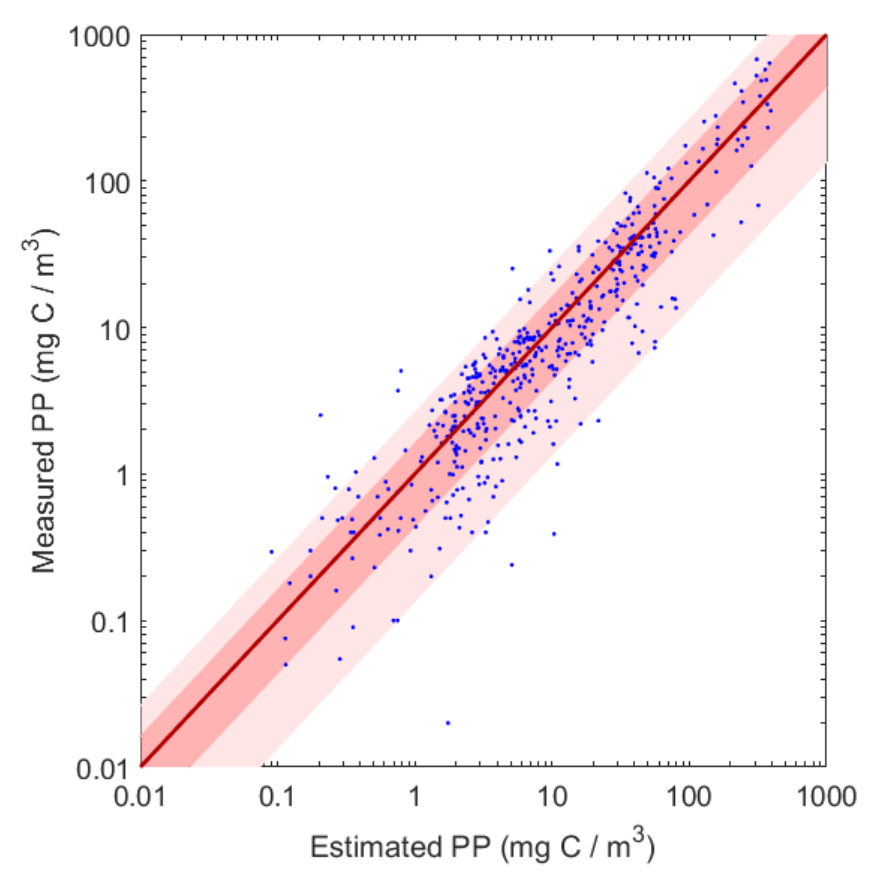

Fig. 4 - Comparison between model estimated primary productivity (Eq. 3) and measured primary productivity. Thick red line is the 1:1 line. Dark pink shows 68\% confidence limits. Light pink shows $95 \%$ confidence limits. 
Contact: mstukel@fsu.edu

\section{II - Application to P1706 Field Data}

Chlorophyll concentrations were measured by R. Goericke using the acidification method with samples taken either from Niskin bottles (cycle measurements and measurements made on cross-feature or alongfeature transects) or from the ship's flow-through system (surface samples taken during SeaSoar surveys). Nutrient concentrations were measured by autoanalyzer on $50-\mathrm{mL}$ frozen samples that had been filtered at sea through a $0.1-\mu \mathrm{m}$ cartridge filter. Surface PAR was determined as daily average for the 24-hours following sample collection (to closely match assumptions used when conducting bottle incubations on previous cruises). PAR data was available from the R.V. Revelle's meteorological (MET) system. For cycle data, percent surface irradiance (PSI) was determined as the average PSI at sample collection depth on daytime CTD casts collected during the 24hours following sample collection. CTD data was retrieved from the CCE LTER DataZoo website and had been processed by $\mathrm{R}$. Goericke. During transect sampling PSI data was typically not available, because we did not spend 24 hours at a particular station. Thus for transect data we computed PSI using beam transmission data. For casts

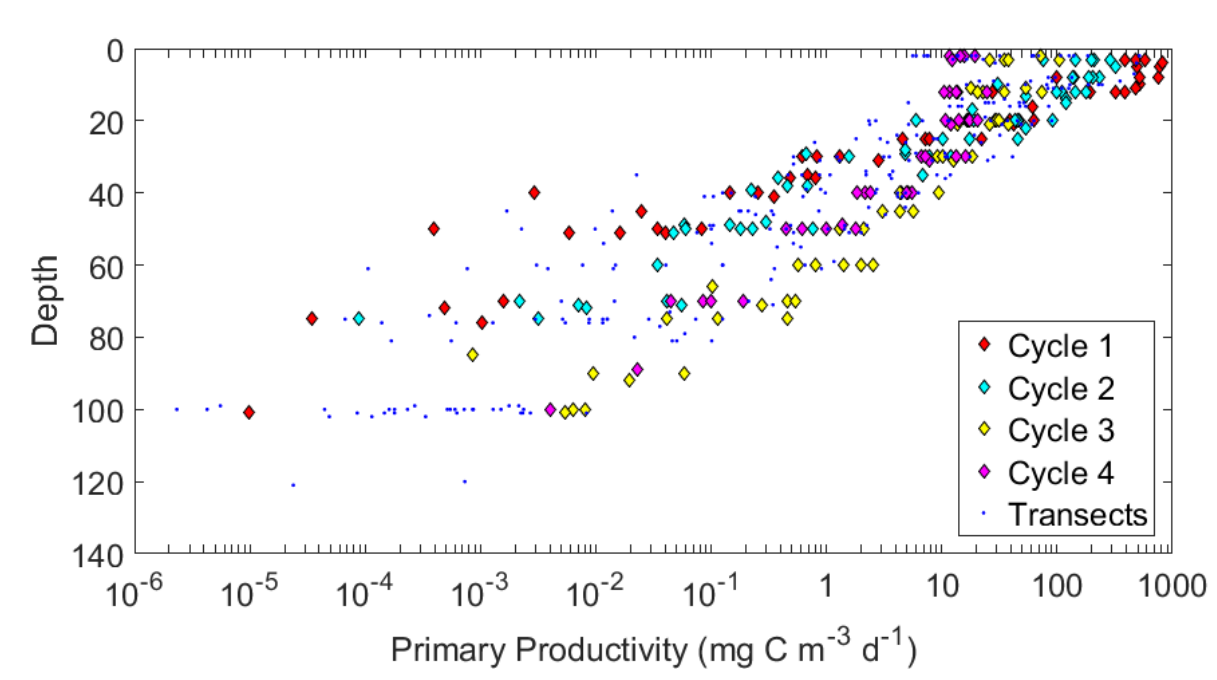

Fig. 5 - Primary productivity as a function of depth on the P1706 Cruise, computed using Eq. 3.

on which beam transmission and ambient PAR were available, we computed the light extinction coefficient and regressed the light extinction coefficient against beam transmission $\left(R^{2}=0.33, p<<10\right.$

${ }^{10}$ ). This relationship between light extinction coefficient and beam transmission was then used to compute depth-varying light extinction coefficients and PSI for casts when PSI was not directly measured by CTD. In a comparison of primary productivity computed using the beam-c data to primary productivity computed using the in situ PAR measurements, the $\mathrm{R}^{2}$ was 0.88 with $\mathrm{p}<<10^{-10}$. We then applied Eq. 3 and multiplied by Chl to determine primary productivity estimates (Fig. 5). Error in Eq. 3 was propagated to individual data points and summary data.

\section{III - Model validation with independent growth rate measurements}

Phytoplankton growth rate estimates were measured daily at six depths in situ during Lagrangian cycles. Growth rate measurements were made using two-point "mini-dilution" protistan grazing experiments (Landry et al. 1984; Landry et al. 2008). Experiments were conducted in 2.7-L polycarbonate bottles placed inside mesh bags hanging off of an in situ array with a 3x1-m drogue centered in the mixed layer (Landry et al. 2009; Landry et al. 2012). These experiments provide chlorophyll-based growth rate estimates. To convert these estimates to carbon-based productivity, we need to know the Chl a 
Contact: mstukel@fsu.edu

concentration (measured during the experiment) and the $\mathrm{C}: \mathrm{Chl}$ ratio of the ambient phytoplankton community, which was not determined experimentally. To estimate C:Chl ratios, we used the Geider et al. (1997) model as modified and parameterized for the CCE by Li et al. (2010). We first used this algorithm to predict C:Chl ratios for the P0605, P0704 and P0810 cruises, because direct microscopybased estimates of $\mathrm{C}: \mathrm{Chl}$ in situ $\mathrm{C}: \mathrm{Chl}$ ratios were available for these cruises (Taylor et al. 2012). We found that at the $95 \%$ confidence limit, in situ measurements were between $25 \%$ and $462 \%$ of the estimated value, while at the $68 \%$ confidence interval (i.e., one standard deviation) the in situ measurements were between $44 \%$ and $178 \%$ of the estimated value.

Comparison between the algorithm-based and dilutionbased estimates of primary productivity showed excellent agreement (Fig. 6). When only comparing paired samples, the mean primary productivity estimated using the algorithm was $120 \mathrm{mg} \mathrm{C} \mathrm{m}^{-3} \mathrm{~d}^{-1}$ with a standard deviation of $190 \mathrm{mg} \mathrm{C} \mathrm{m}^{-3} \mathrm{~d}^{-1}$; for the dilution-based estimates the mean was $111 \mathrm{mg} \mathrm{C} \mathrm{m}^{-3} \mathrm{~d}^{-1}$ with a standard deviation of $206 \mathrm{mg} \mathrm{C}$ $\mathrm{m}^{-3} \mathrm{~d}^{-1}$. The non-parametric Spearman's rank correlation between the two estimates was $0.86\left(\mathrm{p}<<10^{-6}\right)$. The median misfit between the two estimates was $1.9 \mathrm{mg} \mathrm{C} \mathrm{m}^{-2} \mathrm{~d}^{-1}$, suggesting negligible biases between the two approaches. The median absolute value of the misfit was $9.6, \mathrm{mg} \mathrm{C}$ $\mathrm{m}^{-2} \mathrm{~d}^{-1}$, while the median absolute value of the percent error was $41 \%$.

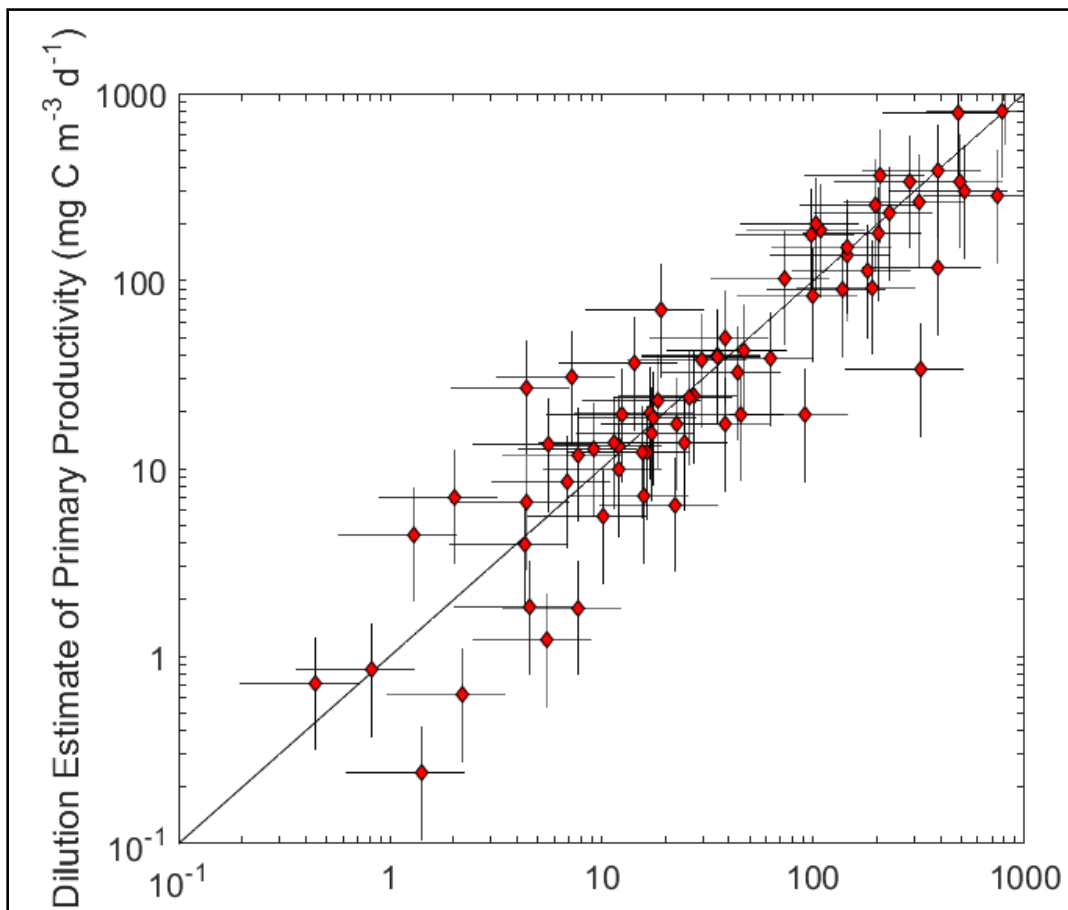

Algorithm Estimate of Primary Productivity $\left(\mathrm{mg} \mathrm{C} \mathrm{m}^{-3} \mathrm{~d}^{-1}\right.$ )

Fig. 6 - Comparison of CCE-P1706 primary productivity estimated with our algorithm (Eq. 3, x-axis) and primary productivity estimated from protistan grazing dilution experiments (y-axis). Error bars equate to one standard deviation of the uncertainty in each measurement.

\section{ACKNOWLEDGMENTS}

We thank the captains and crews of the R.V. Melville, R. V. Revelle, R. V. Knorr, R. V. Thompson, and R. V. Sikuliaq as well as our many collaborators in the CCE LTER Program. Data used in this manuscript can be found on the CCE LTER DataZoo website: https://oceaninformatics.ucsd.edu/datazoo/catalogs/ccelter/datasets. This work was funded by NSF Bio Oce grants to the CCE LTER Program: OCE-0417616, OCE-1026607, OCE-1637632, and OCE1614359. 
Contact: mstukel@fsu.edu

\section{REFERENCES}

Geider, R., H. Macintyre, and T. Kana. 1997. Dynamic model of phytoplankton growth and acclimation: responses of the balanced growth rate and the chlorophyll a: carbon ratio to light, nutrientlimitation and temperature. Mar. Ecol. Prog. Ser. 148: 187-200.

Krause, J. W. and others 2015. Variability in diatom contributions to biomass, organic matter production and export across a frontal gradient in the California Current Ecosystem. J. Geophys. Res. Oceans 120: $1032-1047$.

Landry, M. R. and others 2008. Depth-stratified phytoplankton dynamics in Cyclone Opal, a subtropical mesoscale eddy. Deep-Sea Res. II 55: 1348-1359.

Landry, M. R., L. W. Haas, and V. L. Fagerness. 1984. Dynamics of microbial plankton communities: experiments in Kaneohe Bay, Hawaii. Mar. Ecol. Prog. Ser. 16: 127-133.

Landry, M. R. and others 2012. Pelagic community responses to a deep-water front in the California Current Ecosystem: overview of the A-Front Study. J. Plankton Res. 34: 739-748.

Landry, M. R., M. D. Ohman, R. Goericke, M. R. Stukel, and K. Tsyrklevich. 2009. Lagrangian studies of phytoplankton growth and grazing relationships in a coastal upwelling ecosystem off Southern California. Prog. Oceanogr. 83: 208-216.

Li, Q. P., P. J. S. Franks, M. R. Landry, R. Goericke, and A. G. Taylor. 2010. Modeling phytoplankton growth rates and chlorophyll to carbon ratios in California coastal and pelagic ecosystems. J. Geophys. Res. Biogeosci. 115: G04003.

Morrow, R. M., M. D. Ohman, R. Goericke, T. B. Kelly, B. M. Stephens, and M. R. Stukel. 2018. Primary productivity, mesozooplankton grazing, and the biological pump in the California Current Ecosystem: Variability and response to El Niño. Deep-Sea Res. I 140: 52-62.

Stukel, M. R. and others 2017. Mesoscale ocean fronts enhance carbon export due to gravitational sinking and subduction. Proc. Natl. Acad. Sci., US 114: 1252-1257.

Taylor, A. G., R. Goericke, M. R. Landry, K. E. Selph, D. A. Wick, and M. J. Roadman. 2012. Sharp gradients in phytoplankton community structure across a frontal zone in the California Current Ecosystem. J. Plankton Res. 34: 778-789. 